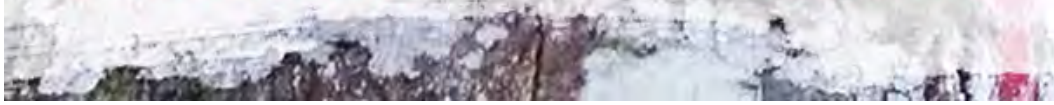

\title{
FORMAÇÃO / ATUAÇÃO DOCENTE E ENSINO DE ARTE: VISÃO \\ DOS PROFESSORES DE ARTES VISUAIS A RESPEITO DAS \\ TECNOLOGIAS CONTEMPORÂNEAS
}

\section{TRAINING / ACTING TEACHERS AND ART EDUCATION: ARTS TEACHERS VISION ABOUT VISUAL TECHNOLOGY CONTEMPORARY}

DOI: http://dx.doi.org/10.5965/1984317812032016183

Luana Pavesi Pera, Stéfani Rafaela Pintos da Rocha, Valéria Metroski de Alvarenga - UDESC

\begin{abstract}
RESUMO
Neste artigo, objetivamos identificar qual a visão dos professores de Artes Visuais no estado de Santa Catarina sobre as tecnologias contemporâneas, tanto no que diz respeito a sua formação docente quanto sobre o ensino de arte. Para tal, usufruímos da pesquisa qualitativa, por esta permitir a coleta de informações relevantes para este estudo, a partir da fala dos sujeitos envolvidos. Contamos com o apoio dos seguintes autores: Loyola (2009), Barreto (2009), Bertoletti (2014) e Pimentel (2002). Constatou-se que a maioria dos professores entrevistados realizaram cursos na modalidade Ensino a Distância (EaD), em sua formação continuada, ou fizeram algum curso sobre essa temática. Vê-se que os professores se mostram interessados e tentam abordar/utilizar as Tecnologias da Informação e da Comunicação (TIC) em suas aulas, mas, muitas vezes, devido a uma formação superficial sobre essa temática, assim como pela precária infraestrutura do colégio, no que tange a recursos básicos para a realização desta, os professores trabalham pouco com as tecnologias contemporâneas.
\end{abstract}

PALAVRAS-CHAVES: Formação docente, TIC, Educação a distância, Ensino de Arte.

\begin{abstract}
In this article, we aimed to identify the vision of visual arts teachers in the state of Santa Catarina on contemporary technologies both on their teacher education and for the teaching of art. To this end, we enjoy the qualitative research for this permit to collect relevant information for this study from the speech of the subjects involved. We count the support of the following authors: Loyola (2009), Barreto (2009), Bertoletti (2014) and Pimentel (2002). It was found that most of the teachers interviewed taken courses in distance education mode, as did a course on this subject. It is seen that teachers may be interested and try to address / use ICT in their lessons, but often due to a superficial education on this topic, as well as the school's infrastructure when it comes to basic resources to carry out this the little teachers work with contemporary technologies in the classroom.
\end{abstract}

KEYWORDS: Teacher education, ICT, Education distance, Art Education. 


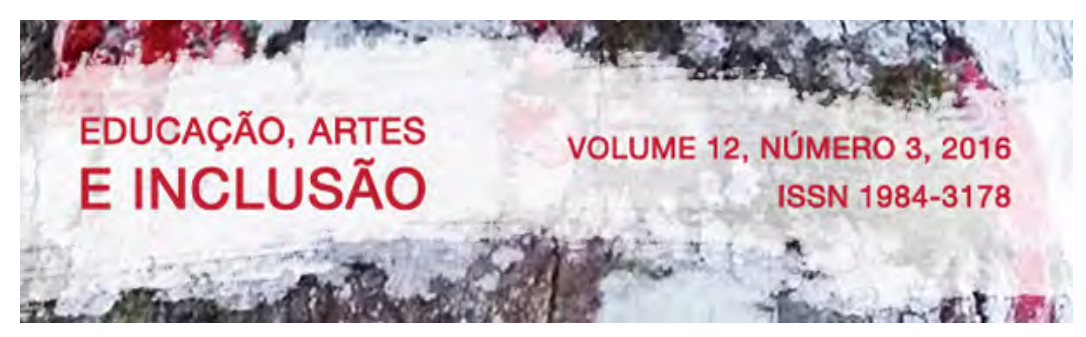

\section{INTRODUÇÃO}

$\mathrm{Na}$ escola nos deparamos com inúmeros desafios que comprometem o trabalho do professor: a superlotação das salas de aula, o sucateamento dos materiais tecnológicos, a falta de acessibilidade e também problemas na infraestrutura de modo geral. Pensando nessa realidade comum a grande maioria das escolas da rede estadual e municipal de Florianópolis (SC), com o intuito de identificarmos qual a visão dos profissionais catarinenses sobre as tecnologias contemporâneas, tanto na formação docente quanto no ensino de arte, entrevistamos vinte professores de Artes Visuais que lecionavam a disciplina de arte na Educação Básica do estado de Santa Catarina. Essa ideia surgiu a partir de uma série de debates que realizamos enquanto estudantes de mestrado em Artes Visuais do Programa de Pós-Graduação em Artes Visuais da Universidade do Estado de Santa Catarina (PPGAV/UDESC), em 2013, nos quais se discutiu a escola, a formação de professores, as tecnologias contemporâneas, a inclusão e o ensino de arte. Durante as entrevistas foram abordados temas como a Educação a Distância (EaD), as tecnologias contemporâneas durante a formação de professores, e a participação em cursos ou programas que articulem o uso das Tecnologias da Informação e da Comunicação (TIC) no ensino de arte.

Os entrevistados responderam a (16) dezesseis questões sobre tecnologias contemporâneas, das quais selecionamos quatro que tratavam da formação docente, a saber: (i) "O que pensa a respeito da EaD? Já participou de algum treinamento utilizando ferramenta de EaD?" (ii) "Que cursos você tem feito que articulem o tema tecnologia e ensino de arte? Caso não tenha feito nenhum nesse contexto, existe alguma formação que tenha realizado específica sobre tecnologia ou sobre arte?" (iii) "Nas paradas pedagógicas da sua escola ou rede, o tema tecnologia é abordado? De que forma?" (iv) "Você ou sua escola já participaram de algum programa institucional que articule tecnologia no cotidiano da escola?"

Como apoio teórico, utilizamos os seguintes autores: Loyola (2009), Barreto (2009), Bertoletti (2014) e Pimentel (2002). Sobretudo fizemos uso de uma metodologia qualitativa tendo por base Silverman (2009). Segundo este autor, a pesquisa qualitativa consiste em "[...] estudar fenômenos simplesmente indisponíveis em qualquer lugar” (2009, p.51), nesse sentido optamos por coletar dados diretamente com os docentes que atuam nas redes de ensino municipal e estadual de Florianópolis (SC). Dessa forma, usufruímos dessa metodologia, por permitir a coleta de informações relevantes para o estudo a partir da fala dos 


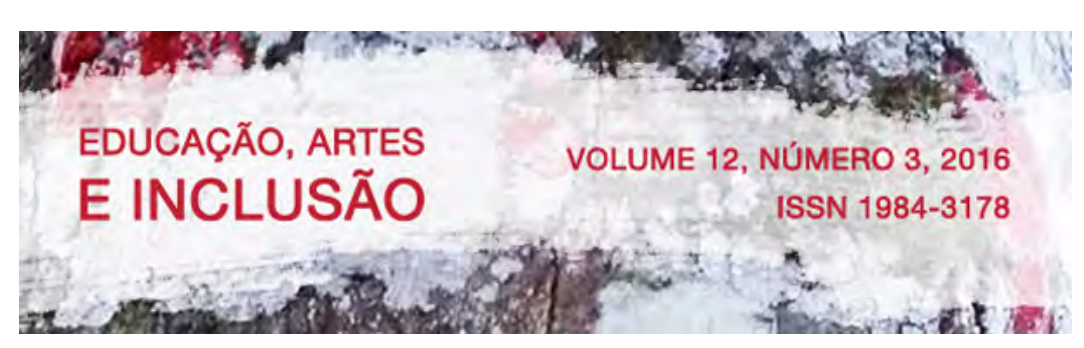

sujeitos envolvidos, pressupondo que os educadores entrevistados apresentem conhecimento prático que oriente suas ações individuais e que possam servir como fonte de pesquisa para professores em formação. Este artigo foi dividido em três subtópicos, a saber: (1) "Tecnologias da Informação e Comunicação e Formação docente"; (2) "Relação entre Tecnologias da Informação e Comunicação e o ensino de arte” e (3) “A visão dos professores atuantes na Educação Básica sobre a Educação a distância”.

\section{TECNOLOGIAS DA INFORMAÇAO E COMUNICAÇÃO E FORMAÇÃO DOCENTE}

Não obstante a presença cada vez maior das Tecnologias da Informação e Comunicação em nosso cotidiano, as escolas ainda não conseguiram alcançar as necessidades mínimas com relação a uma boa estrutura física, como salas de informática com acesso à internet de boa qualidade, por exemplo. Em muitas instituições de ensino, podemos encontrar a sala de informática em desuso por falta de suporte técnico, ou ainda, quando temos equipamentos em bom estado, não são suficientes para o número de estudantes de cada turma. Além desses problemas técnicos, há poucos cursos de formação voltados para esse fim. Mesmo sendo um assunto corrente em sala de aula, são ferramentas pouco utilizadas pelos professores tanto porque faltam os equipamentos necessários quanto porque muitos docentes não possuem intimidade com o uso de computadores e Datashow em um nível mais amplo. Sendo assim, muitas vezes, o uso das TIC se resumem a uma simples veiculação de imagens.

As TIC podem ser utilizadas em benefício do conteúdo trabalhado em sala de aula, como uma forma de ampliá-lo, diversificando as possibilidades de abordagem dos temas e permitindo o uso de novos recursos. Também se tornam mais atrativas nos dias atuais, já que a maioria dos estudantes manipula com facilidade as ferramentas tecnológicas e muitas vezes são eles próprios que ensinam seus professores sobre como operar um programa ou utilizar outro recurso.

Nas universidades tem-se acesso aos conteúdos em sala de aula por meio do uso frequente do computador e de outras mídias, o que acaba fazendo com que os acadêmicos se acostumem a vivenciar processos de ensino-aprendizagem por intermédio da tecnologia. Por outro lado, sabemos que nas escolas este acesso é limitado, muitas vezes em razão da falta de 


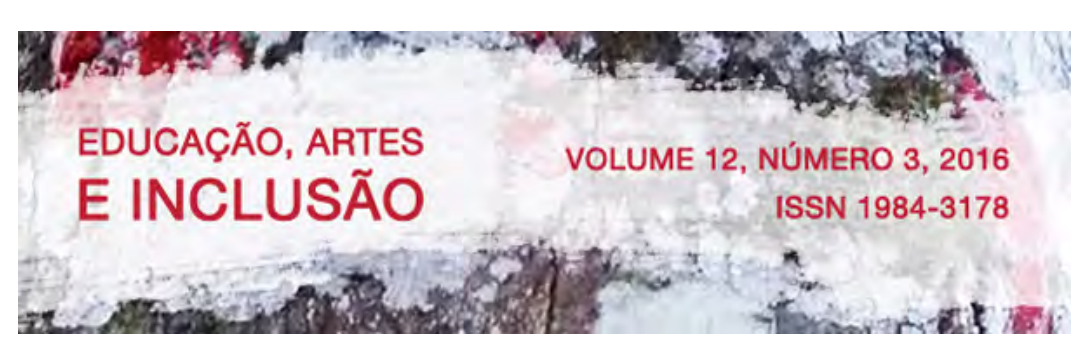

estrutura, como já mencionado, e também pela carência de conhecimento sobre como utilizar a TIC a favor da educação.

Para Loyola, a TIC

(...) diz respeito aos recursos tecnológicos que permitem o trânsito de informações, que podem ser os diferentes meios de comunicação (jornalismo impresso, rádio e televisão), os livros, os computadores etc. Apenas uma parte diz respeito a meios eletrônicos, que surgiram no final do século XIX e que se tornaram publicamente reconhecidos no início do século XX, com as primeiras transmissões radiofônicas e de televisão, na década de 20. Os meios eletrônicos incluem as tecnologias mais tradicionais, como rádio, televisão, gravação de áudio e vídeo, além de sistemas multimídias, redes telemáticas, robótica e outros. (2009, pp.124125).

Por essa perspectiva, os saberes socializados na escola, assim como as informações consultadas por meio dessas tecnologias precisam ser discutidas na formação de professores, como ferramentas inerentes ao contexto atual da educação e como parte do processo de aprendizagem.

A discussão e a valorização sobre as TIC necessitam ser ensinadas tanto durante a formação inicial dos professores, tendo em vista os Parâmetros Curriculares Nacionais, as Diretrizes Curriculares Nacionais da Educação Básica e as Diretrizes Curriculares Nacionais dos Cursos de Graduação - licenciaturas, que recomendam o uso de tecnologias em sala de aula, quanto na formação continuada. No entanto, professores relatam que muitas vezes não usufruem dos computadores disponíveis, pela falta de conhecimento dos recursos e de como integrar esses aparelhos com o que é discutido em sala de aula. A formação docente necessita acompanhar a escola como um todo, bem como aprender a problematizar conteúdos utilizando diferentes recursos para auxiliar na aprendizagem dos alunos. Nesse sentido,

(...) as TIC não podem ser recontextualizadas apenas para simplificar ou substituir as práticas sociais, especialmente nos países ao sul da dita "sociedade global da informação" e, mais especialmente ainda, no contexto brasileiro, marcado por profundas desigualdades. Diante da modernização conservadora, representada pela digitação do que era feito com lápis e papel, e da ilusão de que o acesso à informação está enfim democratizado, as TIC são uma adição que pode redimensionar as 


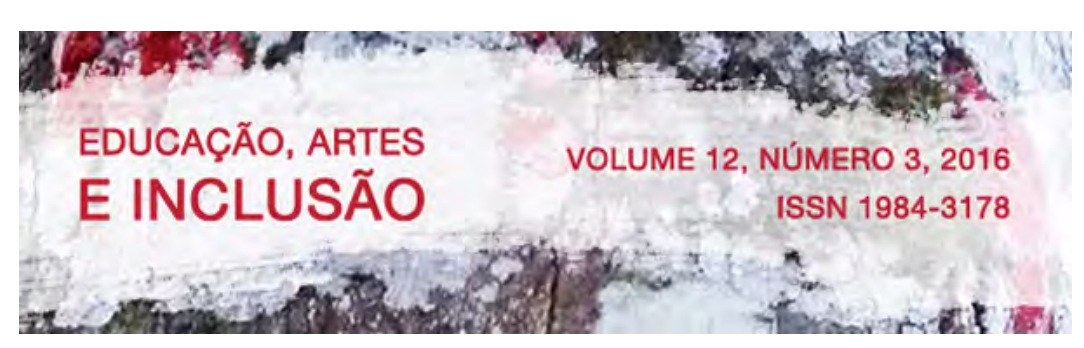

As influências positivas das TIC no ensino de arte vão além da acessibilidade às imagens de obras de arte com uma resolução adequada para sala de aula. Hoje é possível transitar virtualmente pelos corredores de um museu localizado em outro território geográfico, por meio de sites disponíveis na internet. Além do acesso virtual facilitado, os espaços culturais igualmente apropriaram-se das tecnologias, intuindo uma abordagem mais interativa e direcionada às especificidades do seu público alvo, o que pode propiciar a ida de estudantes a estes locais.

Da mesma forma, a exploração desses meios no processo de produção artística introduz potencialidades de criação visual a partir da apropriação da linguagem plástica e multimidiática. As produções de materiais educativos virtuais também contribuem no âmbito educacional. O uso de recursos tecnológicos com viés para pesquisa amplia a comunicação e a interação dos estudantes através de jogos, aplicativos, redes sociais e outros meios, possibilitando aos docentes novas formas de contextualização e de desdobramentos dos conteúdos.

As TIC possibilitam que o ensino de arte ultrapasse e redimensione o "conteúdo comum/habitual" e torne o processo de ensino-aprendizagem algo diferenciado, dinâmico e inovador. No entanto, o professor de arte precisa dominar os recursos para, assim, poder propor determinadas atividades. Uma formação docente inicial consistente e uma formação continuada ininterrupta, nessa área, fazem-se extremamente necessárias para promover resultados favoráveis na atuação profissional do professor de arte. Afinal, "conhecer o instrumento de trabalho e as possibilidades que ele oferece é essencial, mas ir além da mera aplicação dessas possibilidades é fundamental” (PIMENTEL, 2002, p.117).

Nesse sentido, o domínio técnico e reflexivo dos docentes sobre a utilização das TIC é determinante para um ensino crítico, por meio da vinculação de informações conectadas ao contexto no qual se inserem, atentando para a ampliação das possibilidades de produção em arte de forma inclusiva, com intermédio das tecnologias assistivas. O uso desses meios em favor do ensino capacitado deve ser incentivado na formação continuada dos professores. Nesse processo, é possível também às instituições de ensino procurar meios de ampliar a infraestrutura das escolas, visando à apropriação do viés tecnológico, buscando equipamentos e outros meios que são disponibilizados por editais e pelo governo para este fim. 


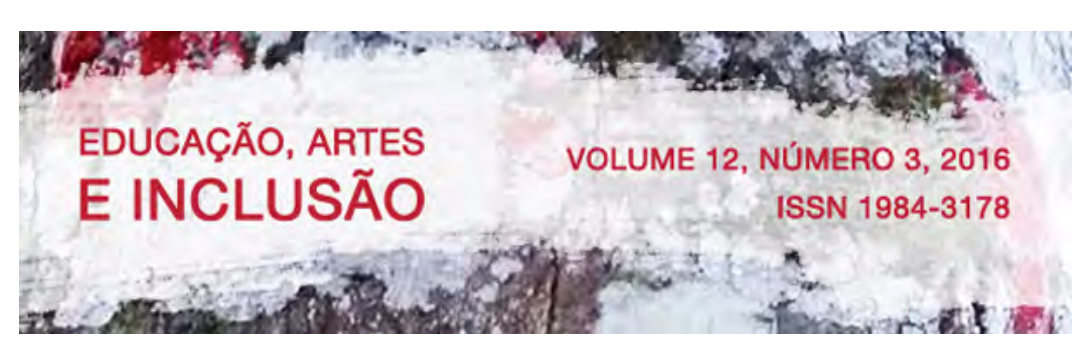

Outro ponto preponderante é a importância da Educação a Distância na difusão do ensino de arte no Brasil. Nas últimas décadas, houve um aumento significativo das graduações que capacitam professores para lecionarem Arte. No entanto, o número de cursos de arte, no âmbito da visualidade, é restrito quando comparado ao de graduações de outras áreas do conhecimento, além de a quantidade de ingressantes nos cursos de licenciatura ser igualmente pequena (FONSECA DA SILVA et al, 2014). Tendo em vista essa realidade, a modalidade de ensino EaD torna viável o acesso à formação nas regiões do país que não dispõe de graduações nessa área.

Segundo a pesquisa de Sampaio (2013) baseada em um levantamento de dados realizado junto ao MEC, registrou-se a existência de 18 Instituições de Ensino Superior brasileiras credenciadas para a oferta de cursos de licenciatura em Artes Visuais à distância. Cabe ressaltar que esses cursos criam inúmeros polos e cada polo oferta um número elevado de vaga. A pesquisadora afirma ainda que no Brasil são formados mais professores para a Educação Infantil e para o Ensino Fundamental I por meio da modalidade EaD do que pela educação presencial. Nessa mesma perspectiva, Gatti (2014) constatou que houve um aumento dos cursos de licenciatura na modalidade $\mathrm{EaD}$ nas últimas décadas. Tal fato pode ter sido impulsionado pela própria legislação. A LDB n 9.394/96 afirma, em seu artigo 80, que: "O Poder Público incentivará o desenvolvimento e a veiculação de programas de ensino a distância, em todos os níveis e modalidades de ensino, e de educação continuada." Sampaio (2013) relata a existência de uma série de estudos que apontam a importância de se retratar o conhecimento tecnológico de maneira contextualizada, e afirma que um ensino de qualidade requer compreensão das relações entre tecnologia, conteúdo e pedagogia. Isto posto, compreende-se que pesquisas sobre essa temática devem ser ampliadas, visando a um aprofundamento teórico que embase o aprimoramento educacional dessa modalidade no país.

\section{A VISÃO dOS PROFESSORES ATUANTES NA EDUCAÇÃo BÁSICA SOBRE A EDUCAÇÃO A DISTÂNCIA}

Objetivando identificar a visão dos professores de arte atuantes na Educação Básica sobre a $\mathrm{EaD}$, analisamos respostas de uma pesquisa que foi realizada por estudantes de mestrado em Artes Visuais do PPGAV/UDESC, em 2013, a partir de debates sobre escola, 


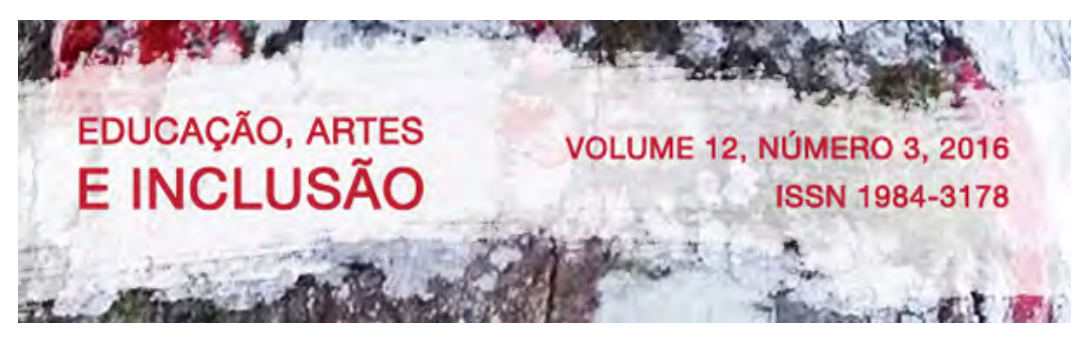

formação de professores, tecnologias contemporâneas, inclusão e o ensino de arte. No total, 20 professores $^{1}$ de Artes Visuais que lecionavam a disciplina de Arte na Educação Básica no Estado de Santa Catarina foram entrevistados ${ }^{2}$. O público participante constituía-se da seguinte maneira: dos vinte (20) entrevistados, oito (8) se formaram antes dos anos 2.000 e doze (12) após este período. Estes possuíam diferentes períodos de experiência na Educação Básica. Um (1) era mestre, treze (13) possuíam especialização e seis (6) graduação. Os professores entrevistados atuavam em turmas que envolvem Ensino Fundamental I $\left(1^{\circ}\right.$ ao $5^{\circ}$ ano) e Ensino Fundamental II ( $6^{\circ}$ ao $9^{\circ}$ ano) até o Ensino Médio. Ao todo eles responderam dezesseis questões sobre tecnologias contemporâneas, das quais selecionamos quatro que tratavam da formação docente ${ }^{3}$. Por vezes, estas foram desmembradas para facilitar a análise.

\section{A primeira questão que analisamos foi: "O que pensa a respeito da Educação a}

Distância?" As respostas foram as mais variadas, tal como segue: “[...] considero uma 'enganação', porque a instituição de Ensino Superior não se compromete com o aprendizado: se o aluno quer, aprende; se o aluno não quer, vai para o mercado de trabalho assim mesmo." (entrevistado 19). Enquanto que outra professora pensa exatamente o oposto: "Acho muito válida a possibilidade de poder aprender à distância, pois muitas vezes os nossos horários e compromissos nos impedem de adquirir conhecimento em algum curso 100\% presencial" (entrevistada 3). Já uma docente que teve experiência com a modalidade EaD relatou que:

Eu particularmente sou bem tradicional, no que diz respeito a preferir o modo presencial. Porém, acredito que o ensino na modalidade à distância é uma tendência que deve ser considerada e ampliada, visto que é uma maneira de otimizar o tempo, sendo que, para mim, só funciona quando o aluno sente um real envolvimento, se desenvolve e tem prazer naquilo que está fazendo. Na contramão disso, muitas vezes o ensino à distância tem sido uma camuflagem para produzir diplomas. No entanto, quem quer aprender, aprende, independentemente de ser presencial ou à distância. A vontade está além do presencial ou virtual. Há muitas pessoas com formação presencial que têm menor desempenho do que outras no mesmo ramo formadas à distância. Todavia, a educação à distância precisa ser muito atrativa, para que não se resuma a um compromisso desgastante de leituras solitárias e dúvidas não solucionadas. (Entrevistada 2)

\footnotetext{
${ }^{1}$ Esses professores foram escolhidos por serem conhecidos dos alunos de mestrado que os entrevistaram. Alguns eram colegas de trabalho ou foram colegas no período da graduação.

${ }^{2}$ Os entrevistados moravam e atuavam em diversos locais, tais como: a capital do estado (diversos bairros), Região Metropolitana de Florianópolis (Palhoça e São José), entre outras cidades de SC, a saber: Rio do Sul, Lages, Tijucas e Apiúna. Este grupo, portanto, é representativo do universo estudado na pesquisa devido as suas diferentes localizações dentro do estado de SC, período de formação inicial e de atuação na Educação Básica.

${ }^{3}$ Devido à quantidade (e a variedade) de questões, algumas delas foram analisadas em outros artigos.
} 


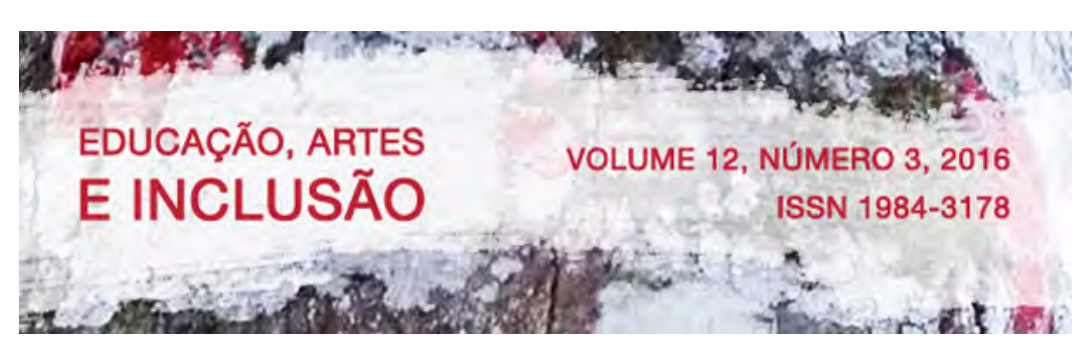

Analisando a fala da entrevistada 2, destaca-se a afirmação que, independentemente da modalidade de ensino, é necessário que o estudante queira aprender; ou seja, o que importa é a sua vontade. Assim, como ela prefere o ensino presencial, afirma que o curso ofertado na modalidade EaD precisaria parecer "muito atrativo", e não poderia ser uma experiência solitária. Sobre esse ponto, é preciso considerar que os cursos na modalidade EaD, em geral, têm chats, fóruns e outros espaços nos quais o estudante pode interagir em tempo real com outros participantes, em diversos locais do Brasil e do mundo. É comum também que um professor-tutor esteja à disposição para tirar dúvidas e orientar os participantes, sempre que necessário. Talvez a experiência da entrevistada 2 tenha sido muito diferente do que normalmente acontece nos cursos $\mathrm{EaD}$, e por isso ela tenha construído uma visão um pouco distorcida sobre eles, quando comenta, por exemplo, que o curso pode acabar se tornando um conjunto de "leituras solitárias e dúvidas não solucionadas". Pois, em sentido oposto, a entrevistada 4, respondendo a mesma pergunta, afirmou: "Existem pontos positivos e negativos. Mas creio que os positivos se sobressaiam. Você pode escolher seu horário de estudo, não precisa sair de casa, há instituições de renome que promovem $\mathrm{EaD}$, teleconferência, grupos de estudo, fóruns e contato com o tutor." Outros relatos reafirmam pontos semelhantes aos já citados, a saber,

\footnotetext{
"A EAD veio auxiliar no ensino superior oportunizando acesso ao ensino superior para todas as pessoas. $\mathrm{O}$ ensino a distância depende muito do empenho do educando na busca do conhecimento, pois os curtos períodos de estudo com o professor em sala de aula dificultam no processo de formação deixando à desejar em alguns conteúdos”. (Entrevistada 7)
}

Outra professora declarou que: "não sou muito fã da EAD, tenho um pouco de resistência, acho um pouco desestimulante estudar sozinho, via uma plataforma. Mas é mais um acesso para algumas situações.” (entrevistada 11). Esses entrevistados afirmam que o tempo escasso com o professor orientando, mesmo que virtualmente, prejudica o processo de ensino-aprendizagem. Acreditamos que algumas pessoas estão muito habituadas ao ensino presencial, por isso apresentam certa relutância em relação a EaD. Enquanto algumas pessoas têm dificuldades e/ou ficam desmotivadas ao estudarem "sozinhas", outras não veem isso como um inconveniente, tal como podemos observar nos relatos a seguir: "Acho mais uma 


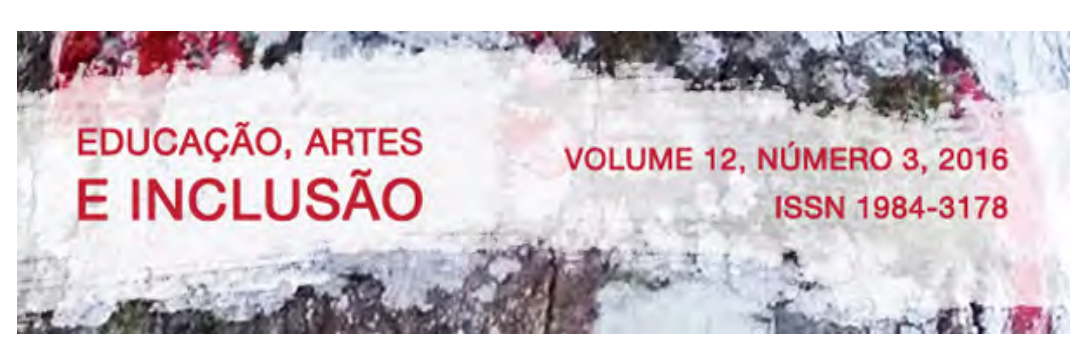

opção pra gente. Tem que se organizar e ter disciplina que aí você realmente aproveita." (entrevistada 12); “[...] muito interessante a forma de diálogo através de fóruns, as atividades publicadas em plataformas onde todos podiam ter acesso e ler, os recursos, os vídeos, e as conferências, tudo muito bem organizado. $\mathrm{O}$ acesso a esse meio de ferramenta funciona muito bem." (entrevistada 20).

No que se refere ao exposto anteriormente, cabe salientar que ao ingressar em um curso na modalidade presencial, muitas vezes somos inseridos em plataformas virtuais, como a plataforma Moodle $e^{4}$ para facilitar o compartilhamento de ações e experiências com um maior número de pessoas de modo diferenciado. Tal plataforma também pode ser utilizada quando se participa de algum projeto institucional como, por exemplo, o PIBID ${ }^{5}$, no qual se socializa com os demais colegas tanto projetos quanto relatos das experiências docentes dos sujeitos envolvidos.

Quanto à análise geral das respostas dos entrevistados, elaboramos um gráfico para facilitar a visualização. Os resultados foram distribuídos em quatro categorias, tal como pode ser visto a seguir:

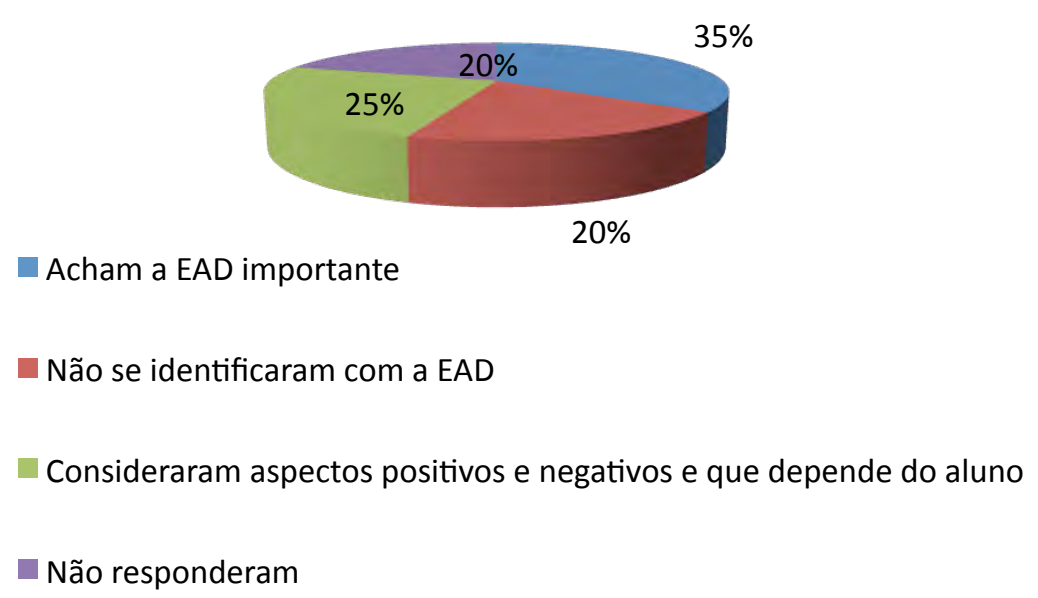

Gráfico 1: Posicionamento dos entrevistados sobre a EaD. (Fonte: autoras)

\footnotetext{
${ }^{4}$ Ambiente virtual de aprendizagem.

${ }^{5}$ Programa de Bolsa de Iniciação à Docência.
} 


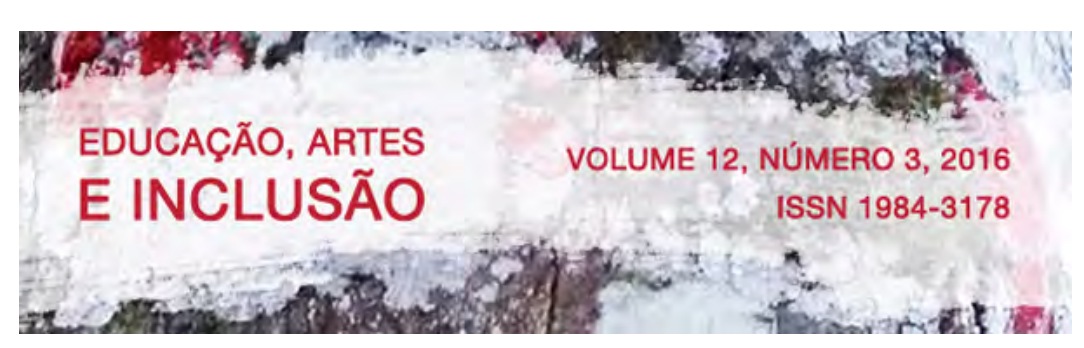

De acordo com o gráfico 1, podemos observar que os entrevistados manifestaram opiniões divergentes em relação à formação na modalidade EaD. Do total de entrevistados, $25 \%$ evidenciaram pontos positivos e negativos, e também afirmaram que, na verdade, os cursos dessa modalidade de ensino dependem muito da disposição do aluno. Já $20 \%$ deles não se identificam com essa modalidade de ensino, alguns firmando seu juízo na comparação entre a experiência de cursos à distância com os de modalidade presencial, tal como observamos no relato da entrevistada 2 . Apurou-se que $35 \%$ dos entrevistados consideram a EaD importante, por motivos que apresentaremos de modo mais detalhado ao longo do texto. Por fim, 20\% dos entrevistados não responderam à questão. Um dos entrevistados ao relatar sobre outro município de Santa Catarina coloca que [...] "o curso de capacitação que a Prefeitura de Palhoça oferece aos professores, pelo menos $30 \%$ é feito por meio de uma plataforma virtual, onde podemos debater, estudar, ou postar atividades sem sair de casa." (Entrevistado 3). Tal aspecto é importante porque permite ao professor adentrar, mesmo que aos poucos, nesse universo tecnológico.

Relacionada com a primeira questão, os entrevistados responderam: "Já participou de algum treinamento utilizando ferramenta de EaD?" Apenas 30\% nunca fez nenhum curso nessa modalidade, enquanto que 55\% chegou a frequentar algum tipo de curso nesse formato, e $15 \%$ dos entrevistados não informaram. Dentre os professores que afirmaram não ter participado de cursos à distância, alguns mostraram interesse em realizá-los, porém ainda não tiveram nenhuma oportunidade. Tendo por base essas respostas, vemos que mais da metade dos entrevistados tiveram acesso e/ou interesse por cursos na modalidade EaD. Tal dado indica que, devido à difusão dos meios tecnológicos e das novas formas do processo de ensino-aprendizagem, os professores, em geral, buscam recursos diversificados para sua formação continuada. As próprias instituições de ensino apostam nessa modalidade, tanto para a formação inicial quanto, com maior ênfase, para a formação continuada.

No que se refere à segunda pergunta, "Que cursos você tem feito que articulem o tema tecnologia e ensino de arte? Caso não tenha feito nenhum nesse contexto, existe alguma formação que tenha realizado específica sobre tecnologia ou sobre arte?", as respostas foram bem variadas. Para ilustrarmos melhor o que foi respondido, construímos o gráfico a seguir: 


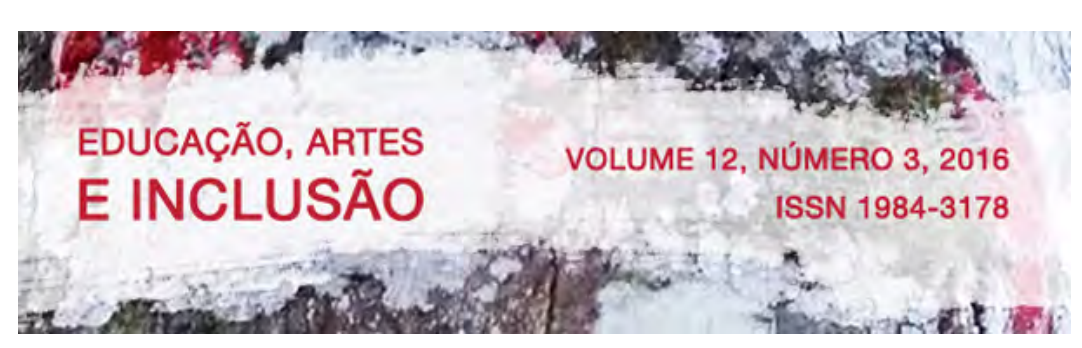

foi em virtude dele que hoje venho realizando os projetos de animação com os estudantes, tanto dos anos iniciais como os da $8^{\text {a }}$ série." É cativante observar, através do relato dessa professora, como um curso sobre arte e TIC pôde modificar e ampliar a sua atuação docente.

Além dos cursos de formação continuada proporcionados pela rede ou que os docentes buscaram em lugares diversos, o papel de disciplinas sobre essa temática na formação inicial do professor, se mostra necessária e evidencia que elas são um suporte para atuação docente, tal como podemos observar no relato da entrevistada 11: “[...] na minha graduação tive várias disciplinas nessa área com professores que atuavam também nessas áreas, como por exemplo: Multimeios, Laboratório de Design Gráfico, entre outras.” A professora relatou-nos:

Participei de um curso promovido pela UFRGS, à distância, ano passado,
sobre o uso dos DVDs arte na escola nas aulas de arte. Encontrei muita
dificuldade em acessar os DVDs, porque não tem em minha escola, e, de
uma semana para a outra, era demasiado complexo ir até um polo que
tivesse, para estudar, bolar planos para trabalhar com os temas em sala, e
demais atividades a serem desenvolvidas semanalmente. Do todo, penso
que desenvolvi muito pouco do que gostaria, não pelo curso em si, mas
para dar conta de locar os DVDs e cumprir as tarefas, mergulhar nelas e
me desenvolver no que era a proposta. (Entrevistada 2)

De acordo com esses relatos, observamos que os cursos foram bem diferenciados, tanto em sua duração quanto em seu enfoque. Observamos também que, muitas vezes, a falta de recursos tecnológicos disponibilizados pela escola, ou até mesmo a infraestrutura desta, dificultaram o processo de realização de um curso na modalidade $\mathrm{EaD}$, tal como relatado pela entrevistada 2. Diferentemente das pessoas que tiveram alguma experiência com a EaD, uma entrevistada disse o seguinte: "Não realizei curso específico. Quando tenho dúvidas recorro ao monitor da sala de informática, para suporte em minhas atividades." (entrevistada 4). Vemos que alguns docentes tornam-se autodidatas, possivelmente por não haver oferta de cursos sobre a temática pela escola, recorrendo à internet quando têm dificuldade em apresentar determinados conteúdos relacionando arte e novas tecnologias, entre outras temáticas.

Quanto à terceira pergunta, "Nas paradas pedagógicas da sua escola ou rede, o tema tecnologia é abordado? De que forma?", 35\% afirmou que essa temática não é abordada, enquanto 55\% relatou que essa temática faz parte dos cursos ofertados pelos colégios durante a formação continuada, e 10\% dos entrevistados não responderam. Vemos, portanto, que a maioria dos professores tem acesso a cursos que abordam a temática das TIC 


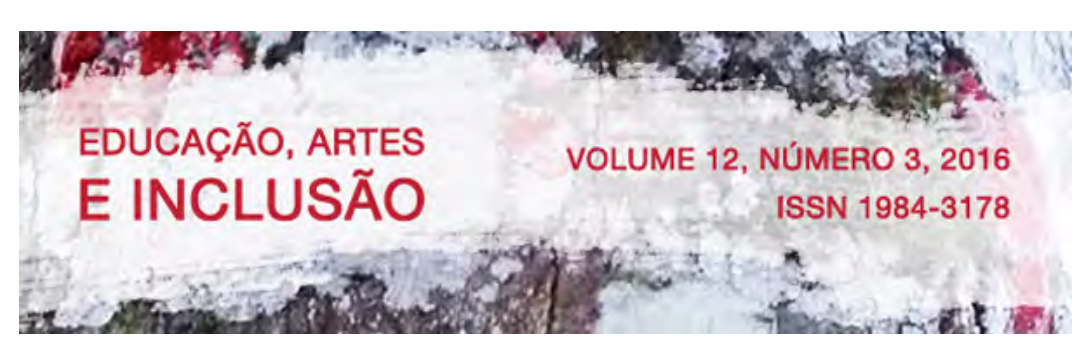

na sala de aula. Apresentamos alguns exemplos do que foi abordado nas escolas, dentro da temática selecionada, por parte dos que responderam afirmativamente: "Tivemos em uma das escolas um palestrante do MEC que sugeriu o uso dos celulares em sala de aula... muitos professores chiaram, mas eu sou completamente a favor." (entrevistado 6). Outra entrevistada disse que obteve orientações a respeito da parte mais técnica dos materiais relacionados com as TIC: “[...] são repassados os novos equipamentos adquiridos pela escola, a organização para uso, etc." (entrevistado 10). Enquanto outra entrevistada afirmou que "[...] o tema é abordado muito superficialmente." (entrevistado 19). Outra professora relatou que: "Sim, mas muito pouco em relação a outros, como: dislexia, alunos com $\mathrm{TDAH}^{12}$, dificuldades de aprendizagem, interdisciplinaridade, entre outros" (entrevistada 2). A entrevistada 5 respondeu da seguinte maneira: “Às vezes, as ferramentas tecnológicas ainda são pouco utilizadas pelo restante das professoras que estão quase se aposentando ou são $\mathrm{ACTs}^{13}$ com pouca experiência." Por fim, outra entrevistada afirmou o seguinte:

\begin{abstract}
"Não, até agora não, tudo que eu preciso eu procuro na rede, em sites de universidades, ou cursos específicos. É possível conseguir participar de cursos fora da escola se a diretora estiver de acordo. Mas na rede em que trabalho no momento não tivemos nenhuma abordagem nesse sentido." (Entrevistada 20)
\end{abstract}

Ao observarmos a resposta da entrevistada 20, verificamos que mesmo quando a escola não fornece suporte para os professores no que se refere as TIC, muitos deles buscam se aprimorar por conta própria. É importante notar, que muitas vezes os professores querem participar de cursos fora da escola, mas para isso é necessária uma autorização da equipe diretiva e também a verificação se os cursos que não são ofertados pela rede ajudam na progressão da carreira. Ou seja, para o professor conseguir se aperfeiçoar, ele precisa correr atrás e se organizar, sendo que esse tipo de formação continuada deveria ser ofertada para ele sem maiores complicações, visto que os próprios alunos é que serão os maiores beneficiados.

Tendo por base os relatos anteriores, precisamos ponderar sobre como os cursos que abordam essa temática chegam até os professores. Será que uma orientação técnica sobre como utilizar computadores ou como fazer agendamento e cuidar dos monitores é suficiente? Discutir sobre a importância do uso das TIC basta? Como precisariam ser os cursos que

\footnotetext{
${ }^{12}$ Transtorno do Déficit de Atenção e Hiperatividade.

${ }^{13}$ Professores Admitidos em Caráter Temporário (ACTs).
} 


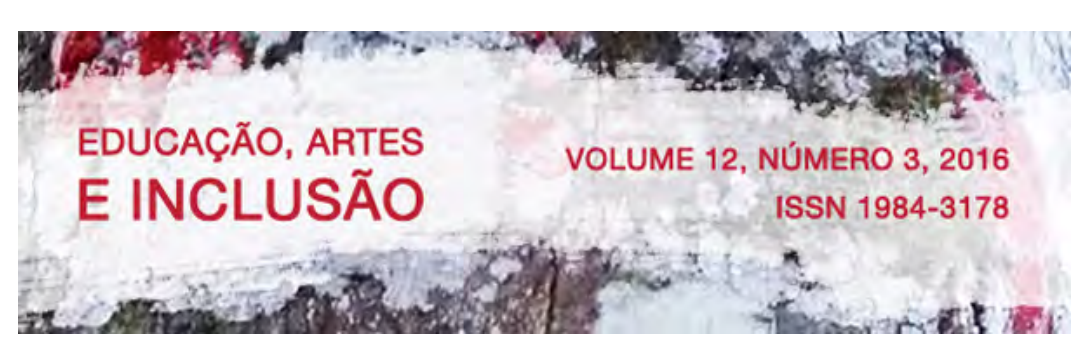

abordam as TIC associadas ao ensino de arte para que o professor possa, de fato, se apropriar dos cursos a ponto de ressignificá-los em suas aulas? Infelizmente, as respostas para essas questões resultariam em uma nova pesquisa e um novo artigo, no entanto, cabe colocá-las aqui como questões em aberto para refletirmos sobre os cursos que são ofertados, quando são ofertados.

Outro ponto nos chamou atenção nesses relatos; mais especificamente a fala da entrevistada 5: segundo ela, o fato de muitos professores estarem se aposentando, assim como a presença de jovens com pouca experiência adentrando o espaço escolar, dificulta o uso das novas tecnologias, pois, em geral, pressupõe-se que os professores de idade mais avançada não dominam bem esses meios, e portanto têm dificuldades em trabalhar com eles em sala de aula, enquanto os mais jovens dominam melhor as TIC, mas ainda podem ter dificuldades em aplicá-las, até mesmo podem temer a utilização desse recurso no ensino de arte, devido à pouca experiência. Apesar disso, sabemos que existem diversas exceções: há professores de diferentes faixas etárias, com períodos de experiência bem diversificados, que inovam em sala de aula utilizando as TIC, muitas vezes por causa de cursos que abordam como trabalhar esse conteúdo em sala de aula e/ou por interesse do próprio docente em pesquisar a respeito.

No que se refere à quarta pergunta, "Você ou sua escola já participaram de algum programa institucional que articule tecnologia no cotidiano da escola?", $65 \%$ dos entrevistados afirmou que não, $25 \%$ declarou que eles ou a escola em que lecionam já participaram de algo relacionado a esse ponto, e 10\% não respondeu. Os que afirmaram positivamente deram como exemplo o seguinte: "Sim, o projeto da GERED ${ }^{14}$, de formação, [aplicado] no recesso de julho, teve uma etapa à distância." (entrevistado 5). Enquanto outra entrevistada afirmou que:

Institucional propriamente dito, não, mas algumas iniciativas na escola, sim; foram desenvolvidos projetos sobre DROGAS e ELEIÇÕES através das aulas de informática, incluindo pesquisas elaboradas pelos alunos. Também teve um projeto de inclusão de Terceira Idade, onde faziam encontros semanais com um grupo de terceira idade. (Entrevistada 2)

\footnotetext{
14 GERED (Gerências de Educação) é um órgão da Secretaria da Educação de Santa Catarina que presta assessoria às escolas.
} 


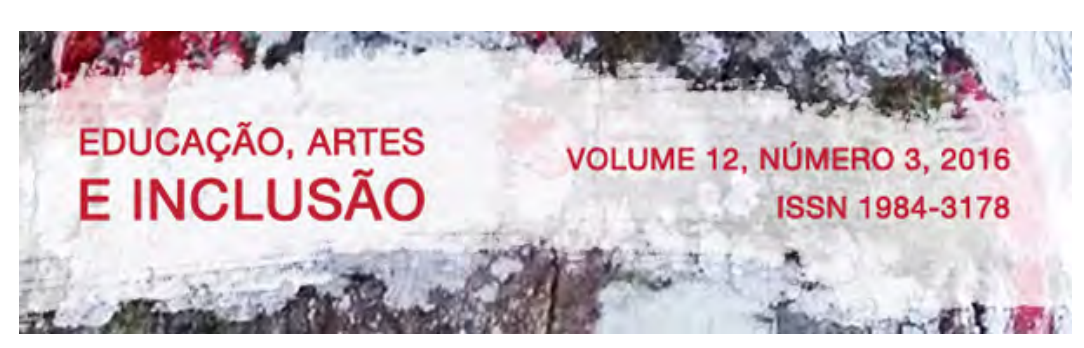

De acordo com esses relatos, observamos que a porcentagem dos professores ou das escolas que tiveram ou têm algum programa institucional articulando novas tecnologias e cotidiano escolar é bastante baixo. É preciso ponderar sobre esse ponto, pois se há pouco incentivo para o uso de novas tecnologias, muitos professores não se motivam a utilizá-las em sala de aula. Além disso, muitas vezes, os docentes não contam com algo duradouro e contínuo que articule teoria e prática escolar, que lhes proporcione uma formação/atuação mais ampla. Se houvesse mais programas institucionais abordando essa temática, mesmo que realizados na modalidade à distância, possivelmente os professores ficariam mais motivados a explorar esses recursos, e talvez até dividissem as suas experiências com os demais colegas de curso da modalidade EaD.

Após esses relatos, cabe pontuar sobre as reflexões de Fischer (2016), ao problematizar as pesquisas recentes sobre as tecnologias digitais e a comunicação na educação, ela afirma que, "nove entre dez artigos sobre as chamadas tecnologias de comunicação e informação (...) enfatizam a oposição entre uma aprendizagem e um ensino 'tradicionais' e as 'ricas' e 'novas' experiências com computadores e, particularmente, com a internet." (FISCHER, 2016, p.4). Essa autora aponta que essa oposição não auxilia no processo de busca de soluções, pois, em geral, fica-se tecendo "entusiasmados elogios" ou "ferozes críticas" ao uso das TIC, ao invés de verificar os entraves e dúvidas do processo ensino-aprendizagem em relação a elas. Essa forma oposicionista de abordar a temática impede a circulação de ideias novas sobre o ponto em questão. Enfim, é preciso valorizar e incentivar o uso das TIC, mas de forma crítica, consciente e criativa. E não podemos deixar no esquecimento outras formas de interação e possibilidades no processo de ensinoaprendizagem que são tão importantes quanto.

Retomando o aspecto das TIC aliadas ao ensino de arte, Alvarenga (2014) apresenta algumas possibilidades de atividades práticas sobre o uso dessas tecnologias na Educação Básica, a saber: (1) fotografia (associado ao retrato e ao autorretrato na história da arte; fotografia de modelos na mídia, problematização dos estereótipos; light painting; fotografar detalhes e buscar conexões da fotografia com a abstração, etc.); (2) cinema (analisar aspectos constitutivos dos filmes, criar curtas, abordar a edição de vídeos, etc.); (3) vídeo-arte (apresentar artistas contemporâneos que trabalham com isso; abordar criticamente a vídeoarte em relação ao cinema tradicional); (4) stop motion (criar narrativas usando o próprio 


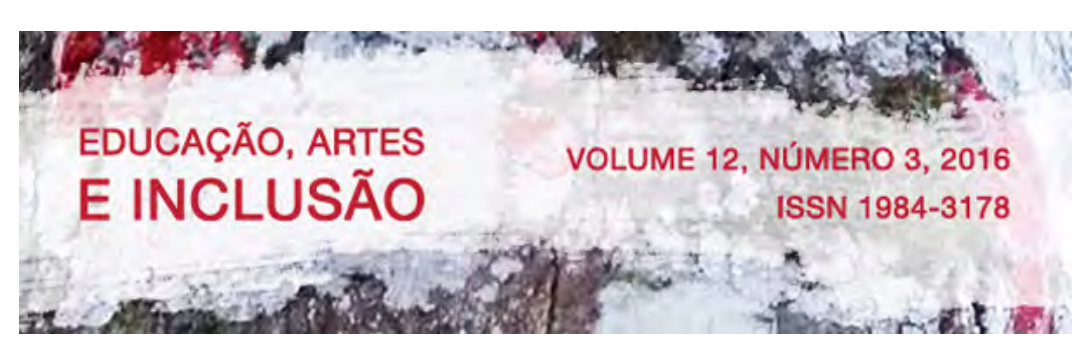

corpo, massinha de modelar ou objetos diversos; abordar aspectos do pré-cinema e dos desenhos animados); (5) museus virtuais (visitar museus nacionais e internacionais sem sair da escola, usando os próprios celulares dos alunos ou o laboratório de informática da escola); (6) redes sociais (criar páginas na internet sobre arte, crítica de arte, campanhas associando arte e conscientização sobre a sociedade contemporânea, criação de blogs sobre arte, etc); (7) programas de criação e manipulação de imagens (explorar programas que possibilitem a criação de desenhos, de história em quadrinhos ou de interferência imagética, pode-se partir das próprias fotos que os alunos manipulam - melhoram - para colocar em redes sociais) e (8) aplicativos (sobre artistas, jogos relacionados com arte, etc).

Há inúmeros cursos on-line gratuitos sobre essas temáticas, assim como artigos de relatos de experiência de professores da Educação Básica que podem auxiliar os professores a incorporar as TIC em suas práticas de ensino de Arte. E, para os professores que não são muito familiarizados com essas tecnologias, os próprios alunos podem auxiliar nos aspectos técnicos. Enfim, as TIC podem ser boas aliadas do ensino de arte.

\section{CONSIDERAÇÕES FINAIS}

Considera-se importante a utilização das tecnologias no ensino de arte, como meio de ampliação da formação estética dos estudantes, pois facilita o acesso à informação e a expansão do repertório imagético, contextual, onde se compõem novas possibilidades de produção e fruição. No entanto, para que isso ocorra, é necessário que os docentes possuam o domínio técnico e reflexivo desses meios, a fim de que haja uma absorção adequada do conhecimento levado para as aulas de arte, potencializando assim a apropriação das TIC e permitindo uma maior interação entre os envolvidos no processo de ensino-aprendizagem.

Conforme o exposto, observamos que muitos docentes identificaram pontos positivos e negativos sobre os cursos na modalidade EaD. Outra parcela afirmou ter tido poucos ou nenhum curso com abordagem em tecnologias contemporâneas, durante a formação continuada ofertada pelas escolas, e que estes, quando ofertados, eram, em geral, superficiais. Por fim, a maioria dos docentes afirmou ter feito os cursos por vontade própria, os quais articulavam o ensino de arte e as novas tecnologias. Vemos, portanto, que os docentes 


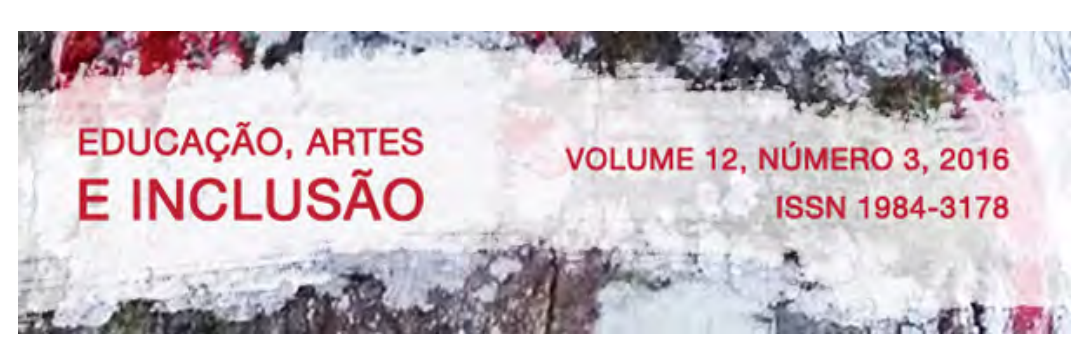

investem na sua formação e sentem falta de cursos mais aprofundados, de iniciativa do Estado e/ou Município. Tais instituições deveriam promover mais cursos nessa modalidade de ensino e incentivar os docentes a realizá-los, visto que alguns entrevistados afirmaram que tem interesse em fazer cursos de $\mathrm{EaD}$, mas ainda não tiveram a oportunidade.

Faz-se necessário, também, mais pesquisas na área de educação sobre como o conteúdo é abordado nesses cursos à distância, visto que alguns entrevistados afirmaram que, muitas vezes, esses cursos são superficiais ou abordam apenas questões técnicas e não aspectos do processo de ensino-aprendizagem. Tais pesquisas poderiam auxiliar na remodelação dos cursos e atrair mais professores. Diante desse quadro, vemos que é preciso que as instituições educacionais ampliem a oferta de cursos na modalidade $\mathrm{EaD}$ e também que forneçam formação continuada com enfoque em tecnologias contemporâneas articuladas ao ensino, para que possamos ter uma atuação docente cada vez mais conectada com o nosso tempo.

\section{REFERÊNCIAS}

ALVARENGA. V. M. Artes Visuais e Novas Tecnologias na Educação Básica: atividades possíveis. Revista Educação, Artes e Inclusão. VOLUME 10, NÚMERO 2, ANO 2014 ISSN 1984-3178. pp. 33-49.

BARRETO, Raquel Goulart. Discursos, Tecnologias, Educação. Rio de Janeiro. EdUERJ, 2009. (Série Pesquisa em Educação. Práticas de Linguagem).

BRASIL. Lei no 9.394, de 20 de dezembro de 1996. Estabelece as diretrizes e bases da educação nacional. Disponível em: < http://www.planalto.gov.br/ccivil_03/leis/19394.htm>. Acesso em: 14 de out. 2016.

BERTOLETTI, Andréa. $\mathbf{O}$ ensino de arte na contemporaneidade: perspectivas frente às tecnologias digitais. Anais do VIII Simpósio Nacional da ABCiber - Comunicação e Cultura na era de tecnologias midiáticas onipresentes e oniscientes, 2014.

FISCHER, Rosa Maria Bueno. Problematizar a pesquisa em comunicação e tecnologias: questões éticas e poéticas. Anais da Reunião Científica Regional da ANPED. Educação, movimentos sociais e políticas governamentais. Paraná, 2016. p.1-15.

FONSECA DA SILVA, M.C.R. et al. Análises sobre licenciaturas em Artes Visuais: 


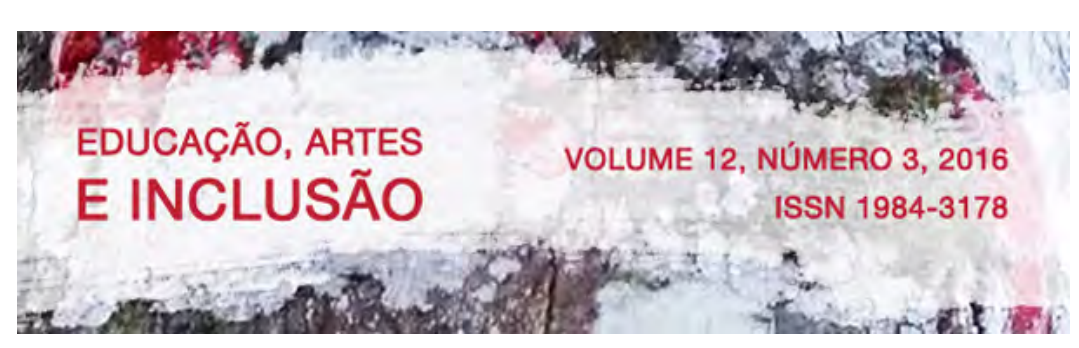

situação no Brasil e no estado de Santa Catarina, 2014 (X Encontro do Grupo de Pesquisa Educação, Arte e Inclusão).

GATTI, B. A. A formação inicial de professores para a Educação Básica: as licenciaturas. Revista USP. São Paulo, n. 100, p. 33-46. dezembro/janeiro/fevereiro 20132014.

LOYOLA, Geraldo Freire. me adiciona.com - Ensino da arte + Tecnologias contemporâneas + Escola pública. Dissertação de mestrado. Belo Horizonte, UFMG, 2009. Mestrado em ${ }^{15}$ Artes.

PIMENTEL, Lucia Gouvêa. Tecnologias contemporâneas e o ensino da arte. In: BARBOSA, Ana Mae (org.) Inquietações e mudanças no ensino de arte. São Paulo: Editora Cortez, 2002. p. 113-121.

SAMPAIO, Jurema Luzia de Freitas. O que se ensina e o que se aprende nas Licenciaturas em Artes Visuais a distância?. Art\& (São Paulo. Online), v. 1, p. online, 2013.

SILVERMAN, David. Interpretação de dados qualitativos: métodos para análise de entrevistas, textos e interações. Porto Alegre: Artmed, 2009. 